\section{(6) OPEN ACCESS}

\title{
Contextual design choices and partnerships for scaling early child development programmes
}

Kate M Milner, ${ }^{1,2}$ Raquel Bernal Salazar, ${ }^{3,4}$ Sunil Bhopal, ${ }^{5,6}$ Alexandra Brentani, $^{7}$ Pia Rebello Britto, ${ }^{8}$ Tarun Dua, ${ }^{9}$ Melissa Gladstone, ${ }^{10}$ Esther Goh, ${ }^{11}$ Jena Hamadani, ${ }^{12}$ Rob Hughes, ${ }^{5,13}$ Betty Kirkwood, ${ }^{1}$ Maya Kohli-Lynch, ${ }^{1,14}$ Karim Manji, ${ }^{15}$ Victoria Ponce Hardy, ${ }_{1}^{1}$ James Radner, ${ }^{16,17}$ Muneera Abdul Rasheed, ${ }^{18}$ Sonia Sharma, ${ }^{19}$ Karlee L Silver, ${ }^{20}$ Cally Tann, $^{\oplus 1,21}$ Joy E Lawn ${ }^{1}$

- Additional material is published online only. To view please visit the journal online (http://dx.doi.org/10.1136/ archdischild-2018-315433).

For numbered affiliations see end of article.

\section{Correspondence to} Dr Kate M Milner, MARCH Centre, London School of Hygiene \& Tropical Medicine, Keppel St, London WC1E7HT, UK; kate.milner@Ishtm.ac.uk

Received 1 August 2018 Revised 18 December 2018 Accepted 18 January 2019

\section{Check for updates}

(C) Author(s) (or their employer(s)) 2019. Re-use permitted under CC BY-NC. No commercial re-use. See rights and permissions. Published by BMJ.

To cite: Milner KM, Bernal Salazar R, Bhopal S, et al. Arch Dis Child

2019;104:S3-S12.

\section{ABSTRACT}

Translating the Nurturing Care Framework and unprecedented global policy support for early child development (ECD) into action requires evidence-informed guidance about how to implement ECD programmes at national and regional scale. We completed a literature review and participatory mixed-method evaluation of projects in Saving Brains $₫$, Grand Challenges Canada $₫$ funded ECD portfolio across 23 low- and middle-income countries (LMIC). Using an adapted programme cycle, findings from evaluation related to partnerships and leadership, situational analyses, and design for scaling ECD were considered. 39 projects (5 'Transition to Scale' and 34 'Seed') were evaluated. 63\% were delivered through health and 84\% focused on Responsive Caregiving and Early Learning (RCEL). Multilevel partnerships, leadership and targeted situational analysis were crucial to design and adaptation. A theory of change approach to consider pathways to impact was useful for design, but practical situational analysis tools and local data to guide these processes were lacking. Several RCEL programmes, implemented within government services, had positive impacts on ECD outcomes and created more enabling caregiving environments. Engagement of informal and private sectors provided an alternative approach for reaching children where government services were sparse. Cost-effectiveness was infrequently measured. At smallscale RCEL interventions can be successfully adapted and implemented across diverse settings through processes which are responsive to situational analysis within a partnership model. Accelerating progress will require longitudinal evaluation of ECD interventions at much larger scale, including programmes targeting children with disabilities and humanitarian settings with further exploration of cost-effectiveness, critical content and human resources.

\section{BACKGROUND}

What is needed to support scaling of early child development?

The Sustainable Development Goals and Global Strategy for Women's, Children's and Adolescents' Health (2016-2030) aim to ensure that every child has the opportunity to thrive, or reach their best developmental potential. ${ }^{12}$ The WHO, UNICEF and World Bank 'Nurturing care for early childhood development: a framework for helping children survive and thrive to transform health and human potential'

\section{Key findings}

1. WHY? Time to accelerate implementation for early child development (ECD): translating unprecedented global policy support, including the Nurturing Care Framework, into action requires evidence-informed guidance about how to implement ECD programmes at national and regional scale.

2. WHAT IS NEW? Contextual design choices: targeted situational analyses are crucial for adaptation and should be guided by pathways to impact (eg, theory of change) and local formative data wherever possible.

3. WHAT TO DO? Partnerships and leaderships: key and emerging networks focusing on action at national level provide a resource for those with responsibilities for programme development and implementation.

4. KEY GAPS? Implementation and research gaps to close: accelerating progress requires more structured tools for situation analyses and design decisions including how to integrate care of children with disabilities and in humanitarian settings. Implementation research to understand impact at much larger scale, over longer time frames and including costeffectiveness data needs to be embedded.

(Nurturing Care Framework, NCF) provides a policy framework to support these ambitions (figure 1). ${ }^{3}$ As well as increased global focus on early child development (ECD), there has been a steady increase in ECD policy uptake with $45 \%$ of low- and middle-income countries (LMIC) having national, multisectoral ECD policies. 4

However, few LMIC have implemented largescale ECD programmes, and there are no consistent measures of coverage and quality. ${ }^{5}$ Hence, to operationalise the NCF, there is increased demand for evidence to inform design, implementation and measurement of ECD programmes at scale. ${ }^{4-8}$

Saving Brains, Grand Challenges Canada (GCC) represents the largest innovation investment in ECD projects in LMIC so far and is a unique opportunity to explore decision processes related to programme design, implementation and scaling in diverse settings. ${ }^{9}$ Saving Brains was designed to support healthy brain 


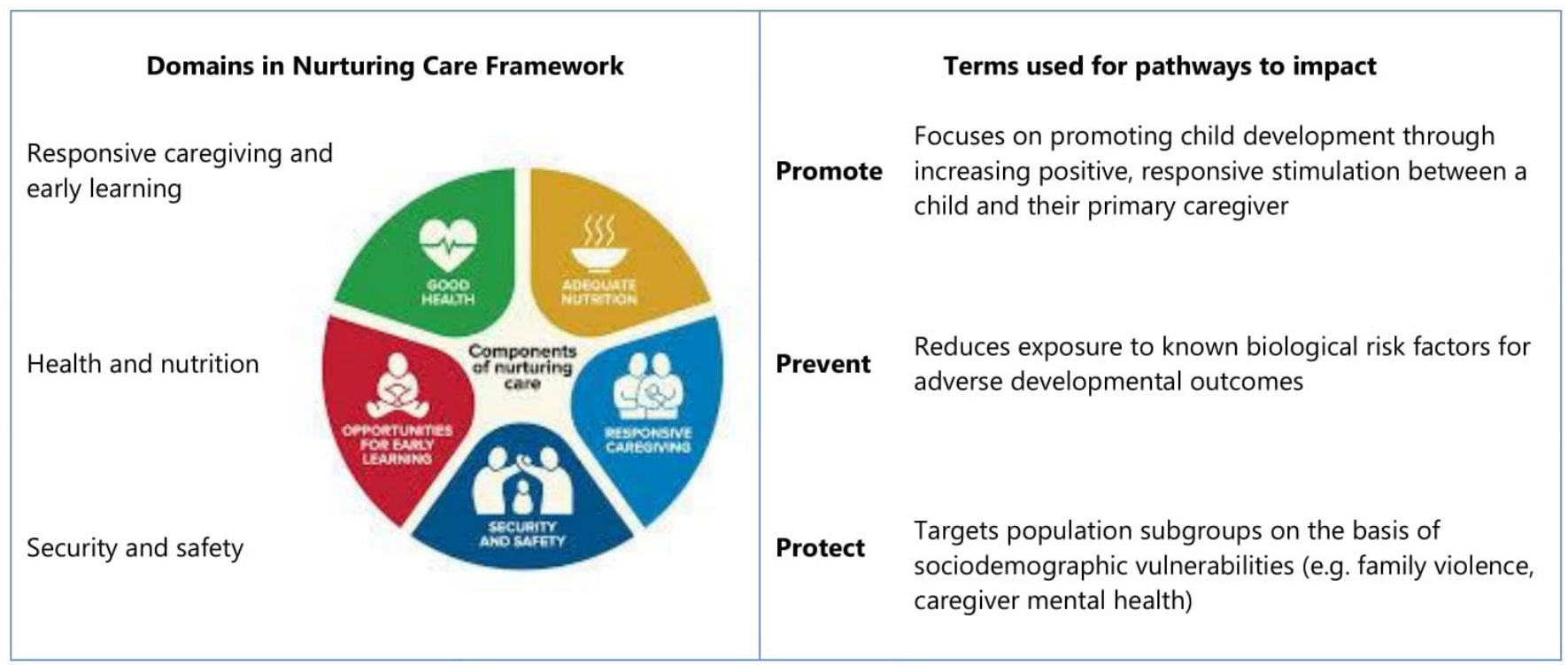

Figure 1 Definitions of domains in the Nurturing Care Framework and corresponding terms used in evaluation of the Saving Brains portfolio.

development for children in the first 1000 days through innovations that prevent brain injury, promote stimulating and responsive environments and protect children from developmental risk factors. ${ }^{9}$ Between 2011 and 2016, Saving Brains invested Can\$43 million in 108 grants to teams based in LMIC. ${ }^{9}$ Most projects were 'Seed' (proof of concept) with 18-24 months' duration and a minority were 'Transition to Scale' (TTS) grants with 2-3 years' duration and the aim to scale up. All are led by LMIC organisations and are supported by a multi-institutional platform that provides technical and practical support. ${ }^{10}$ Saving Brains uses a portfolio-level theory of change to consider pathways to impact (supplementary web appendix figure A). ${ }^{9}$ Our evaluation relates to all Saving Brains Seed and TTS projects completed by February 2017 (supplementary web appendices textbox $\mathrm{A}$, tables $\mathrm{A}$ and $\mathrm{B})$.

\section{Purpose, scope and structure of series}

The purpose of this series is to inform decisions related to design and implementation of ECD interventions at national and subnational levels in diverse LMIC. ECD occurs within a life-cycle continuum, but here we focus especially on pregnancy to 3 years. We have adapted a generic programme design and implementation cycle to apply to ECD (figure 2A) and consider key processes and decision points within that (figure 2B).

Each paper relates to a specific aspect of the programme cycle. This first paper focuses on the centrality of partnerships, leadership, situational analysis and the major decisions in ECD programme design (eg, sectoral entry point, targeted vs universal approaches). Subsequent papers consider monitoring and evaluation, ${ }^{1112}$ financing, ${ }^{13}$ and overall process to scale up. ${ }^{14}$

The first two papers, including this paper, draw directly on mixed-method evaluation of the Saving Brains portfolio, with case studies from the TTS Saving Brains grants, while other papers build on additional analyses.

\section{Objectives of this paper}

1. Describe processes and decision points in an ECD programme cycle for scale-up.

2. Synthesise findings of Saving Brains evaluation related to the ECD programme cycle, specifically: partnership and leadership, situational assessment, adaptation to context and programme design choices.

\section{METHODS}

Objective 1. Describe processes and decision points in an ECD programme cycle for scale-up

Based on literature in other areas of global child health and ECD as well as findings of Saving Brains portfolio evaluation, we adapted a generic programme cycle and systematically considered key decision points in the process of ECD programme design, implementation and scale-up. ${ }^{15-17}$

\section{Objective 2. Synthesise findings from the Saving Brains} portfolio evaluation related to processes and decision points in ECD programming

We completed an impact and process evaluation of projects funded by Saving Brains, GCC, between 2011 and 2016. Evaluation was led by a team from the London School of Hygiene \& Tropical Medicine in collaboration with the Saving Brains partnership, True Point/Harvard University and the WHO. We used a participatory mixed quantitative and qualitative approach to evaluate the portfolio as whole (box 1). Qualitative themes explored were arranged around key decision points in the programme cycle (figure 2A).

\section{RESULTS}

Objective 1. Processes and decisions in an ECD programme cycle for scale-up

Figure 2A,B describes the processes and decision points in programme design, implementation and scale-up according to previously described methods.

Objective 2. Findings from the Saving Brains portfolio evaluation related to $E C D$ programming

Thirty-nine projects were implemented across 23 LMIC between September 2013 and November 2016 including 34 Seed and five larger TTS projects, some of which were being scaled up from previous Seed projects (table 1 and supplementary web appendix table C). Projects were diverse in terms of context, 

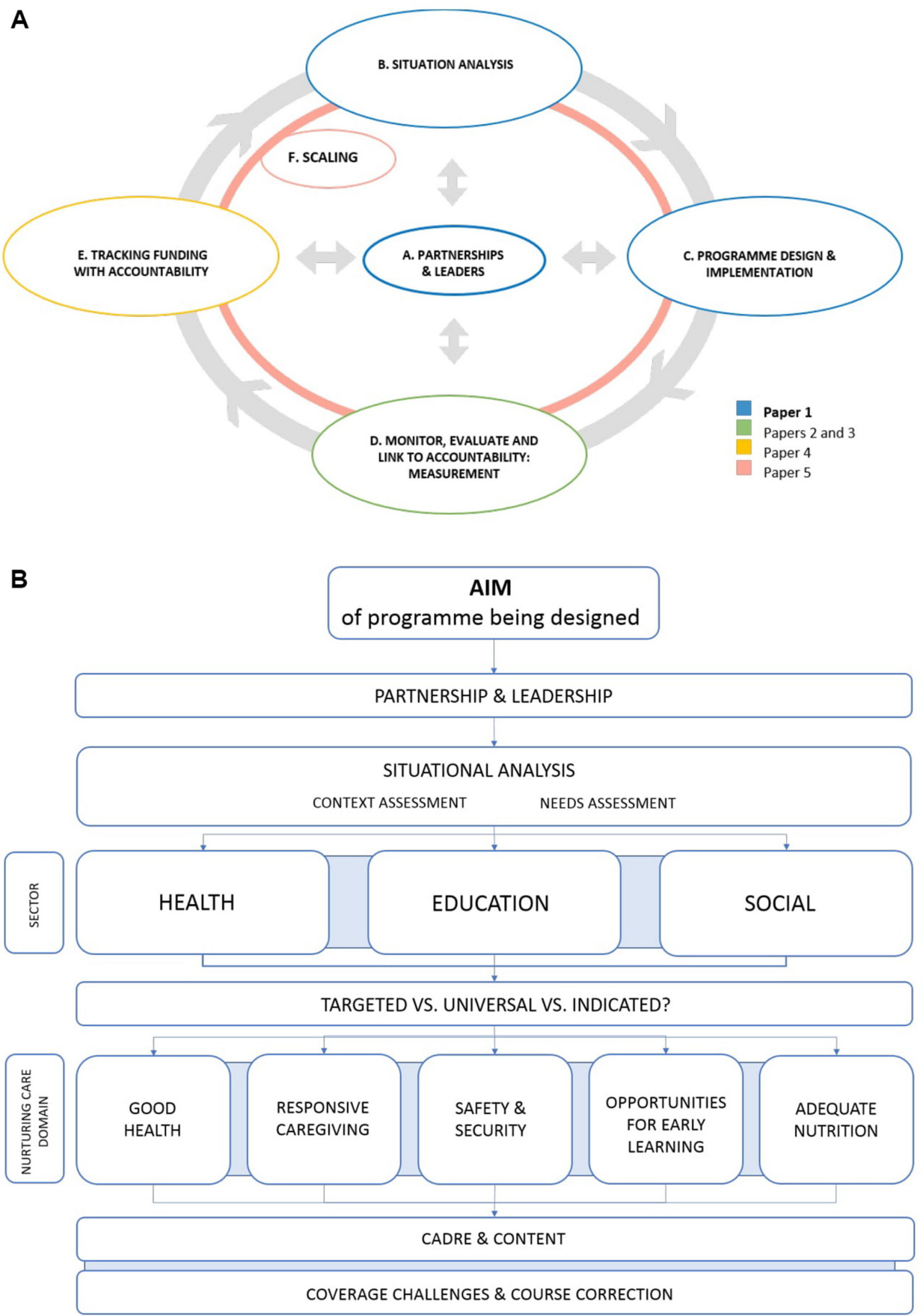

Figure 2 (A) Programme cycle for design, implementation and scaling of early child development programmes. (B) Programme design and implementation decision points for early child development.

design, content, implementation strategy and size $(n=41-2500$ participants). A summary of Seed grants is provided in supplementary web appendix table C. Programme decisions for TTS grants which focused on RCEL are summarised in table 1 with further details of individual programme case studies summarised in boxes 1-4.

\section{Partnerships and leadership}

Multilevel partnerships for scaling

Qualitative data reflected the importance of partnerships to intervention design and implementation. In Seed projects, implementing teams valued technical expertise in ECD, research, monitoring and evaluation. By contrast, TTS teams already had considerable ECD expertise and were led by local groups with established track records. These partnerships, focused towards scaling, were multilevel and typically built on long-standing relationships with community, government, non-governmental organisation (NGO) and academic institutions (table 1).

Leadership at multiple levels

The importance of leadership both at higher political and lower system levels was emphasised. For example, in Bangladesh, the support of government health workers in motivating workers at clinic level, and facility-level support to mobilise practical resources for implementation at local level during Kangaroo 
Box 1 Cameroon and Mali case study: scaling up

Kangaroo Mother Care (KMC) to help newborns survive and thrive

\section{Context}

An established evidence base from high-resource settings demonstrates that developmental care initiated soon after birth can have positive effects on early developmental outcomes among high-risk infants. ${ }^{31}$ KMC for low birthweight (LBW) and preterm newborns is an example of an early nurturing care intervention that has the potential to improve survival and to positively impact on short-term and long-term neurodevelopmental outcomes.

Among the Saving Brains portfolio, one Transition to Scale (TTS) project looked specifically at implementation of KMC for small and preterm newborns in a multicountry low-resource sub-Saharan African setting. This built on previous work showing shortterm and mid-term benefits on survival, neurodevelopment and mother-infant bonding, ${ }^{32}$ and also a 20 -year KMC follow-up cohort that showed significant long-lasting protective social and behavioural effects extending into adolescence and young adulthood. ${ }^{33}$

The TTS project focused on scaled implementation of KMC in Mali and Cameroon, including two 'centres of excellence' and 10 regional health facilities. The intervention package consisted of promotion and support of breastfeeding and skin-to-skin contact after birth for stable LBW newborns, and included home visits up to 28 days of age. The project team examined effect on survival, anthropometric outcomes including head growth, exclusive breastfeeding rates, rates of KMC and KMC education. Early child development outcomes were not directly measured.

\section{Findings}

A key aspect of programmatic learning regarding implementation was the importance of in-country leadership and 'buy in' at all levels, but particularly at individual facility level. Lack of infrastructure, in way of equipment and materials, was highlighted as a key challenge in delivering KMC. Introduction of an E-learning platform to facilitate quality practice was particularly well received, with teams reporting high levels of self-directed knowledge transfer and positive experiences of high-quality training in an easy-to-navigate format.

\section{Implications}

Interventions typically thought of as targeting newborn and child survival also have the potential to promote early child development. Local buy-in from in-country leaders and establishment of local protocols and infrastructure can be crucial to the success of these programmes. E-learning platforms may be a useful adjunct for high quality and coverage of training when implementing at scale.

Mother Care (KMC) scale-up in Mali and Cameroon, was crucial.

\section{Roles of different sectors}

Government partnerships, predominantly health, were key for scaling and sustainability in TTS projects. In Bangladesh, Brazil and Colombia, the focus was on implementation of RCEL programmes through health and social protection services. This required adaptation of interventions to account for case load, incentivisation, intervention strategy and dosage, and meant that projects were more vulnerable to political instability and loss of direct control of implementation. However, these challenges were balanced against reach and perceived sustainability of government services. Furthermore, in spite of challenges, published findings demonstrate the feasibility and effectiveness of integrating interventions into existing government services (boxes 1-4). ${ }^{16-18}$

In the Mobile Crèches project in India, the private sectors (NGOs and construction companies) were chosen as primary implementation partners to reach children not already connected with government health services. Qualitative feedback also highlighted the potential role of the private sector for other reasons (eg, for experience in scaling models). Sectoral partnerships with child protection and disability were not well explored across the portfolio although are the focus of ongoing Saving Brains projects. ${ }^{19}$

Families and communities as partners in design and implementation Active partnership with families and communities was important and was achieved through various methods (ie, inclusion in situational analysis and piloting, participation of family members as front-line workers and through consideration of family perspectives in monitoring and evaluation). One project (Vietnam) specifically focused on father engagement.

\section{Situational analysis and adaptation to context}

Projects were based in Africa, Eastern Europe, the Middle East, Central America and South-East Asia. Seven (30\%), 11 (48\%) and $5(22 \%)$ projects were implemented in low, low-middle and upper middle-income countries, respectively (according to World Bank definitions). ${ }^{20}$ Upper middle-income projects were implemented mostly in Brazil (Since Saving Brains has a partner organisation, Fundação Maria Cecilia Souto Vidigal (FMCSV) in Brazil). Child health, education and equity profiles of project sites varied. Only one project (Democratic Republic of Congo) was implemented in a humanitarian setting (table 1, supplementary web appendix table C).

Detailed understanding of context through formative research and piloting was considered crucial to implementation design and effectiveness. TTS teams using the 'Reach Up' curriculum made adaptations to content, delivery strategy, target population, materials, personnel, training, supervision and sociocultural context to suit their contexts in Bangladesh, Colombia and Brazil (table 1). These adaptations were important to ensure feasibility, acceptability and potential sustainability and scalability of interventions across settings. Context-specific adaptation of parenting programmes in Bangladesh is outlined in box 3 to highlight the importance of ongoing adaptation during implementation and scaling.

In spite of the importance given to situational assessment and contextual adaptation, these factors were typically based on implicit local knowledge in the absence of structured tools to support situational assessment and given an absence of population-level data on ECD.

The importance of understanding financial context was also highlighted repeatedly, however it was difficult for projects to track cost data. One project (Colombia) explored cost in detail (box 4).

\section{Programme design}

\section{Sectoral entry point}

Most project teams (63\%) used health as the primary entry point. RCEL projects were most common and included several larger TTS projects implemented in Bangladesh, Colombia, Brazil and India. Thirty-three per cent of projects combined responsive caregiving with health interventions (typically 


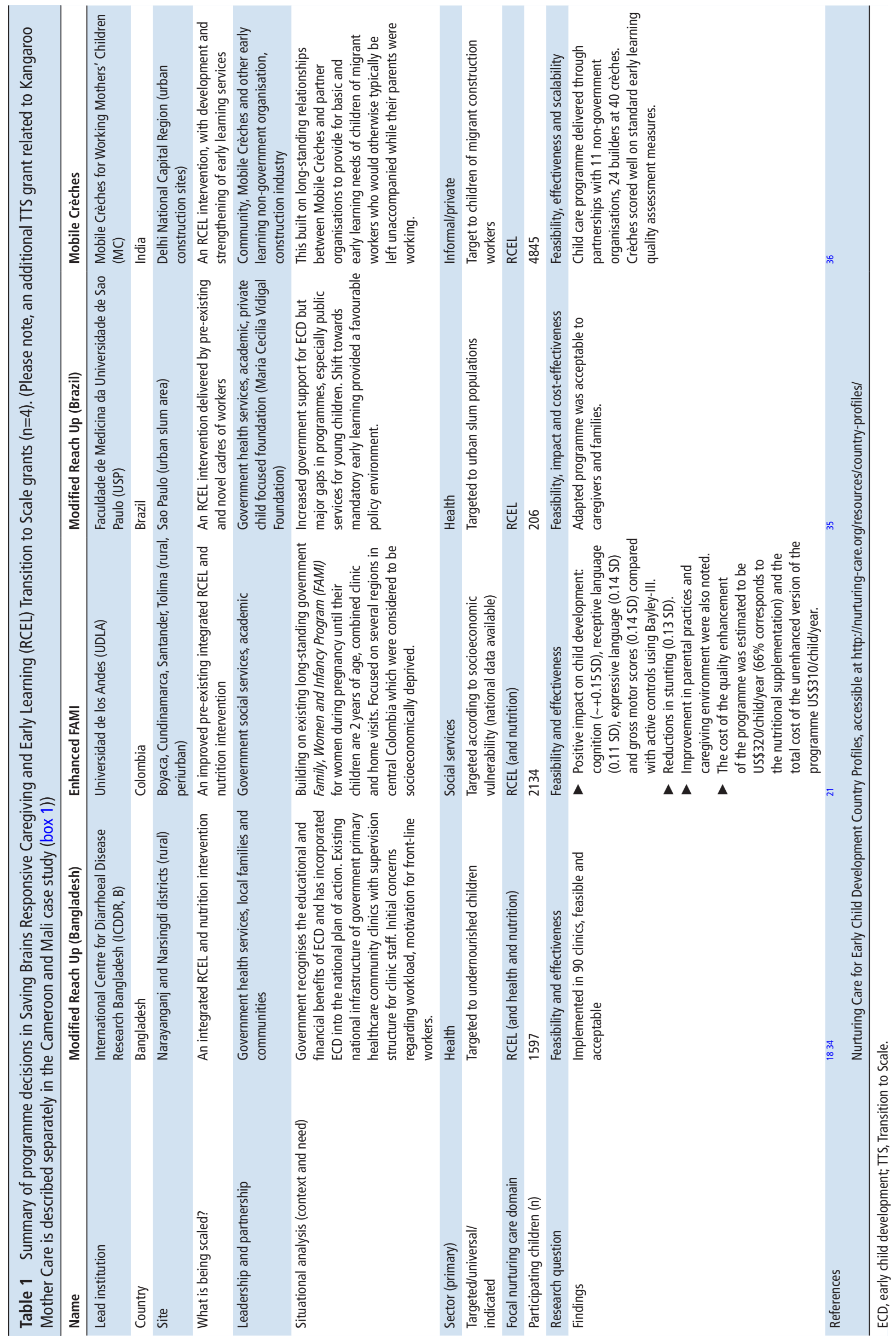


Box 2 Bangladesh case study: designing an integrated

early child development (ECD) intervention for

undernourished children for scale-up through government health services

\section{Context}

In Bangladesh, a diverse and densely populated country, national-level indicators reflect substantial progress in child health over several decades with impressive reductions in overall under-5 mortality, although substantial inequities remain. ${ }^{24}$ There is also high-level governmental recognition of the importance of early child development which has been incorporated into a national plan of action. ${ }^{37}$

Local researchers reviewed integration of responsive caregiving ECD interventions into health and nutrition services in Bangladesh. ${ }^{37}$ Findings suggested that existing ECD programmes through government services were either limited in scope or had not been adequately evaluated. ${ }^{37}$ Conversely, a number of high-quality local intervention trials had previously demonstrated feasibility and effectiveness of responsive caregiving interventions when implemented at small scale. ${ }^{38-44}$ Specifically, previous trials in Bangladesh had demonstrated positive impact of responsive caregiving interventions on early child development outcomes for undernourished children and when integrated with interventions for mothers with depression at small scale. ${ }^{38-44}$

To build on this existing local evidence, scale-up and evaluation of interventions implemented in routine services, a team from the International Centre for Diarrhoeal Disease Research Bangladesh $(I C D D R, B)$ funded by Saving Brains completed a cluster randomised trial to assess impact of a responsive caregiving intervention integrated into routine primary health services.

Researchers built on long-standing relationships with local partners and particularly targeted the government health sector for partnership in scaling in order to support sustainability and to use existing infrastructure, particularly 13000 primary healthcare clinics nationally.

\section{Findings}

Challenges, both anticipated and unexpected, were experienced but not insurmountable. Poor initial attendance at sessions was managed through greater engagement of families and communities in intervention adaptation and implementation design processes. Various incentivisation strategies were considered and tried, however, being mindful of logistics with scaling, strategies that focused on communication, engagement and awareness raising rather than material incentivisation were selected. Changes in government nutrition programmes during the course of implementation which were outside the researchers' control, meant that provision of nutritional supplements was not possible, and therefore the nutritional intervention component focused on counselling only. There were also anticipated challenges with government staff workload, motivation and expectation of remuneration. Engagement of front-line workers as well as existing supervisors in the process of implementation was important in overcoming these challenges.

In spite of these challenges, the responsive caregiving intervention was successfully implemented in 90 clinics with evaluation findings in process. ${ }^{18}$

\section{Implications}

Moving forward, researchers plan to continue with intervention scale-up through government services, noting that their role is

Continued

\section{Box 2 Continued}

likely to change with scaling. Specifically, in the next phase of scaling, transitioning responsibility for staff supervision and training to government workers will be evaluated. ${ }^{18}$ To reach children at geographic distance, engagement of other partners and new delivery strategies are also being considered (eg, non-governmental organisation (NGO) sector, media).

nutrition (53\%) or newborn health (37\%)) (figure 3B). A smaller proportion of projects integrated interventions with other sectors (eg, maternal mental health $(18 \%)$ or child protection (9\%)) (figure 3B). (Since evaluation was completed, subsequent rounds of Saving Brains grants have increased emphasis and an increased number of grants focusing on children's child protection, disability and humanitarian settings. See Archived Requests for Proposals accessible at http://www. grandchallenges.ca/programs/saving-brains/.) Twenty-five per cent was delivered in an early learning/childcare context (figure $3 \mathrm{~B}$ ).

Targeted versus universal

In line with the funder requirements, all projects were targeted on the basis of a range of developmental risk factors, including:

- Health, for example, nutritional status or neonatal risk factors (ie, preterm birth or low birth weight). One project (Jamaica) for children with a non-nutritional chronic disease (ie, sickle cell disease).

- Socioeconomic deprivation.

- Geographic location including rural, remote populations and urban slum populations.

- Ethnicity.

- Maternal mental health. One project (Democratic Republic of Congo) targeted women at risk of depression based on screening.

- Developmental delay. One project (Peru) targeted an at-risk population based on developmental screening. No interventions explicitly focused on children with developmental disabilities. $^{1}$

However, methods for targeting varied and frequently relied on implicit local knowledge in settings where population-level data on child developmental status and risk factors were lacking (supplementary web appendix table C).

\section{DISCUSSION}

Our mixed-method evaluation of the largest donor investment in ECD highlighted important findings of relevance to health professionals and policymakers around the world.

Multilevel partnerships are important for design, implementation and scaling. Our findings add to previous literature emphasising the importance of partnerships between policymakers, implementers in different sectors, communities and researchers. TTS projects built on long-term, well-established relationships with stakeholders at multiple system levels and emphasised the practical importance of leadership at lower as well as higher system levels to support implementation (eg, in KMC scaling in Cameroon and Mali, for health worker engagement in Bangladesh). TTS project experiences also highlight that roles and responsibilities within these partnerships change with scaling (eg, changing responsibilities for health worker training with scaling in Bangladesh and Colombia). ${ }^{1821}$ 
Box 3 Brazil case study: designing an adapted

Responsive Caregiving and Early Learning (RCEL) programme for children in urban slums

\section{Context}

Brazil has made remarkable progress for child nutrition and survival over the past decade, with particularly impressive results in large urban areas. In Sao Paulo, infant mortality has now dropped to 11 deaths per 1000 and prevalence of stunting to less than $10 \%$. However, large socioeconomic disparities remain, especially in urban areas where lower socioeconomic status (SES) families often live in illegal slum settlements characterised by poor hygiene, high levels of environmental pollution and violence. Children growing up in these poor urban settlements are exposed to a high burden of adverse environmental exposures and often lack support of traditional social and family structures in rural communities. Additionally, there is lack of institutional child care for the urban poor: while early childhood care centres (crèches) are commonly used among middle and upper class parents, less than $10 \%$ of the poor urban population targeted by this project benefit from such services. ${ }^{45}$ As in most low- and middle-income countries, Brazil's child policy efforts have historically been focused on child health and formal schooling, which starts at age 6 .

\section{Universal or targeted?}

A large literature suggests that developmental differences emerge in the first 1000 days; even though catch-up at later ages is possible to some extent, early programmes like the ones evaluated here may be the most effective tool to reduce socioeconomic and intergenerational disparities, and thus complement current social protection policies. Over recent years, interest in early childhood care has been increasing in Brazil. However, there has been a gap in public early child development programming for children below school age. ${ }^{46}$ However, the policy environment for development of such services was favourable with a plan to provide mandatory enrolment in kindergarten for all children starting from age 4 by 2015 (bill passed in April 2013). Therefore, researchers from the University of Sao Paulo opted for a targeted approach, focusing their intervention towards children below school age and low SES families from the urban settlements in the western region of Sao Paulo.

\section{Which sector?}

Existing, free government health services (SUS) are primarily used by low SES groups with a reach, according to latest estimates of $55.6 \%$ of urban households in Sao Paulo. Therefore, researchers considered government family health services as a potential platform for implementation of a home visiting programme as a first step towards larger regional or national programmes. Home visiting programmes have been proven effective in improving early child development and maternal well-being in a number of countries, and given Brazil's proven capacity in implementing large-scale social protection and health programmes, this was considered a potentially feasible platform for scaling. Although evidence based, since there were a number of questions regarding implementation of parenting programmes in this context, researchers developed a pilot project which aimed to assess the feasibility, potential impact and cost-effectiveness of established home visiting programmes in the local context.

\section{Findings}

Smith et al recently reported on evaluation of intervention adaptation and implementation in Brazil. ${ }^{35}$ During implementation,

\section{Box 3 Continued}

multiple adaptations were made to the base programme including adaptations of content, delivery strategy (eg, frequency of home visit), personnel and materials. The adapted programme was implemented by both existing government health workers as well as a new cadre of worker or 'community developmental assistants'. Overall, the adapted parenting programme was well accepted by caregivers and front-line workers. Use of a clear structured curriculum, training and supervision approach was considered an important enabling factor. However, challenges were experienced with high turnover and low prioritisation of the intervention by salaried government workovers in the context of their broader workload.

\section{Implications}

Careful consideration of human resource requirements including cadre of worker, case load, scheduling, training and supervision is a key consideration to support feasibility of implementation with further scaling.

Leadership for ECD can be developed through peer networks and 'communities of practice'. We observed peer-peer learning and development of multidisciplinary communities of practice to be useful mechanisms for ECD leadership development at country level. There are an increasing number of such communities being developed, which could serve as a useful resource for policymakers and practitioners alike. For example, the Early Child Development Action Network was established by UNICEF and the World Bank in 2016 to provide one access point to resources and a community of practitioners. ${ }^{22} 23$

Situational analysis and adaptation of ECD interventions to context are crucial but often rely on implicit knowledge and informal processes. Situational analysis and formative data are crucial for intervention adaptation, feasibility, sustainability and scale-up. However, we observed that situational analysis typically relied on implicit knowledge of context rather than a systematic approach, and there were limited data on epidemiological need (ie, population-level child development status and/or risk factors). In other areas of child health (eg, newborn health), structured tools for assessment of context and availability of epidemiological data provide clearer structure for adapting interventions to context. ${ }^{24}$

There are an increasing number of tools to support situational analysis within ECD including World Bank 'Country Profiles' for assessing policy context and the UNICEF situational analysis tool which is available online.

A range of sectoral entry points for RCEL may be effective depending on context. TTS projects demonstrate that multiple sectors provide feasible and acceptable entry points for ECD. The Enhanced Family, Women and Infancy Program (FAMI) and Modified Reach Up (Bangladesh) programmes add to previous literature that demonstrates that RCEL interventions can be adapted and effectively implemented across diverse settings, in both cases through government services. Mobile Crèches demonstrated an alternative entry point through private and informal sectors to successfully engage hard-to-reach children.

All projects were targeted but varied in the approach used to identify their target population, often relying on informal local knowledge. While use of commonly available indicators (eg, socioeconomic data in the Enhanced FAMI programme or health status in the Modified Reach Up (Bangladesh)) is one practical approach, improved population-level data on a 
Box 4 Colombia case study: designing an enhanced

Responsive Caregiving and Early Learning (RCEL)

programme through government services

\section{Context}

Multiple stakeholders emphasised the policy and programming relevance of cost-effectiveness of interventions. Specifically, innovating teams reported strong demand for data on cost and cost-effectiveness, relevant to the local setting. However, across the portfolio, $45 \%$ of teams reported direct costs and very few reported indirect costs. Within the constraints of Seed grants, teams reported that demonstration of cost-effectiveness was their key priority but they lacked technical expertise and other resources to effectively measure this from an early stage. However, among larger Transition to Scale (TTS) grants, an intervention in Colombia to improve the quality of a pre-existing parenting programme was demonstrated to be effective and relatively affordable compared with the cost of various alternatives with lower impacts.

In Colombia, a partnership led by the Universidad de Los Andes sought to improve an existing parenting programme to deliver an integrated responsive caregiving and nutrition intervention to children in a socioeconomically deprived population subgroup. The enhanced parenting programme included incorporation of an early stimulation curriculum inspired by the Reach Up curriculum, nutritional supplementation, and programme provider training and supervision protocols, and was delivered through group meetings. It was evaluated through a cluster (town) randomised controlled trial delivered across 87 towns in three departments in central Colombia for an average of 10.4 months. In control towns, children received the unenhanced government parenting programme (Family, Women and Infancy Program, FAMI).

\section{Findings}

At follow-up, positive effects were noted on child development including improved cognition $(\sim+0.15 \mathrm{SD})$, receptive language (0.11 SD), expressive language (0.14 SD) and gross motor scores (0.14 SD) compared with active controls using Bayley-III. Reductions in stunting (0.13 SD) and improvement in parental practices and caregiving environment were also noted. ${ }^{35}$ These effects were noted even though exposure in the intervention group was lower than intended.

In addition to measuring impact, cost of the enhanced parenting programme compared with local programming alternatives was also evaluated. The cost of the unenhanced government parenting programme was estimated to be US\$310 per child/year while cost of enhancement was US\$320 per child/year. Additional costs included both the pedagogical (US\$122/year) and nutritional (US\$212/year) components. These costs compare favourably to estimated costs of centre-based care for children aged 6 months to 5 years which are estimated to be US $\$ 1100$. Furthermore, the estimated effect of centre-based care compared with home-based care is, on average, only about 0.05 SD. ${ }^{17}$

\section{Implications}

In this middle-income setting the enhancements to existing community-based, parenting programmes compare favourably to centre-based options at a fourth of the cost.

broader range of developmental risk factors (eg, Countdown ECD Country profiles) will enable more effective targeting of other at-risk groups, including children with disabilities. $^{2526}$
Early consideration of pathways to impact and scale is important and can be supported by a 'theory of change' approach. Given that ECD interventions, like those in other inherently interdisciplinary fields (eg, nutrition, mental health), are complex, inter-related and dynamic, it is important to have a programming approach that allows for this complexity, considers pathways to impact and potential challenges to scaling from early stages of design. The Saving Brains portfolio used of a theory of change approach which was valued by multiple stakeholders in encouraging forward planning. This resonates with recent literature in the field which demonstrates that RCEL interventions developed using a theory of change approach are most effective across LMIC. ${ }^{25}$

Evaluation also highlighted scaling as ongoing and adaptive rather than as a separate process that occurs only after initial demonstration of effectiveness. This finding is supported by other literature from both high-income country and LMIC which demonstrates that simple approaches to rapid cycle learning (eg, incorporation of plan-do-act cycles) can strengthen ECD programmes. ${ }^{6} 1627$

\section{Strengths, limitations and research implications}

While this is the largest multicountry evaluation to date, Saving Brains projects were relatively small, of short duration and heterogeneous in design and quality. We now need rigorous evaluation at much larger scale and our work highlights specific gaps including how to strengthen demand; facilitation and governance of partnerships at scale; programme strategies when leadership is lacking; further development of situational tools to improve context description by epidemiology and level of service provision; differentiation of programme designs according to context; and targeted interventions including for children in humanitarian settings and with disabilities, both of which are a focus in ongoing Grand Challenges Canada funded portfolios. ${ }^{28-30}$

Improved population-level data will be important for ensuring equitable coverage to identified target populations. ${ }^{11}$ Identifying population strengths as well as risk factors in programme success will be crucial in respectful cross-cultural adaptation of interventions. ${ }^{6}$

Finally, more research to better understand cost-effectiveness of design and implementation choices is needed. Although the TTS project in Colombia provides a good example of such work and in spite of its recognised importance, many project teams were unable to address this. ${ }^{21}$ Other crucial issues discussed later in this supplement include; monitoring and evaluation, funding and accountability and barriers and enablers to scaling. ${ }^{11-14}$

\section{CONCLUSION}

ECD programme development across LMIC requires targeted situational analysis and practical approaches to incorporating feedback into design, implementation and scaling. Long-term investment in partnership at all levels is crucial as is leadership which can be supported by peer networks and 'communities of practice'. Multiple sectoral entry points are feasible and effective at small scale but ongoing research is needed to inform how to systematically differentiate programme design according to context and to understand impact at much larger scale over longer time periods. Improved data on ECD at population level are needed to promote more effective programme targeting and tracking of coverage and equity with scale-up. Finally, approaches to addressing practical human resource challenges, defining essential intervention content, and monitoring and 
A

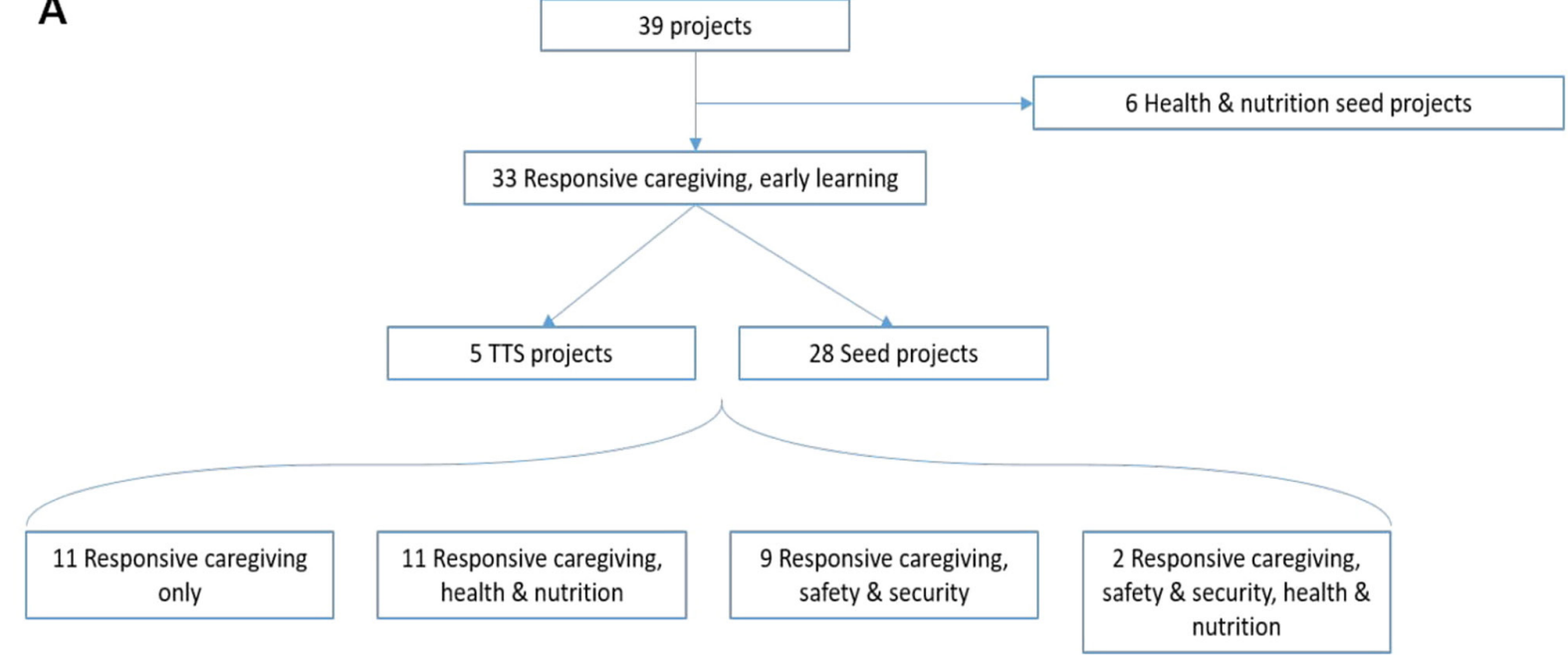

\section{B Pathways to impact}

\section{Mechanism}

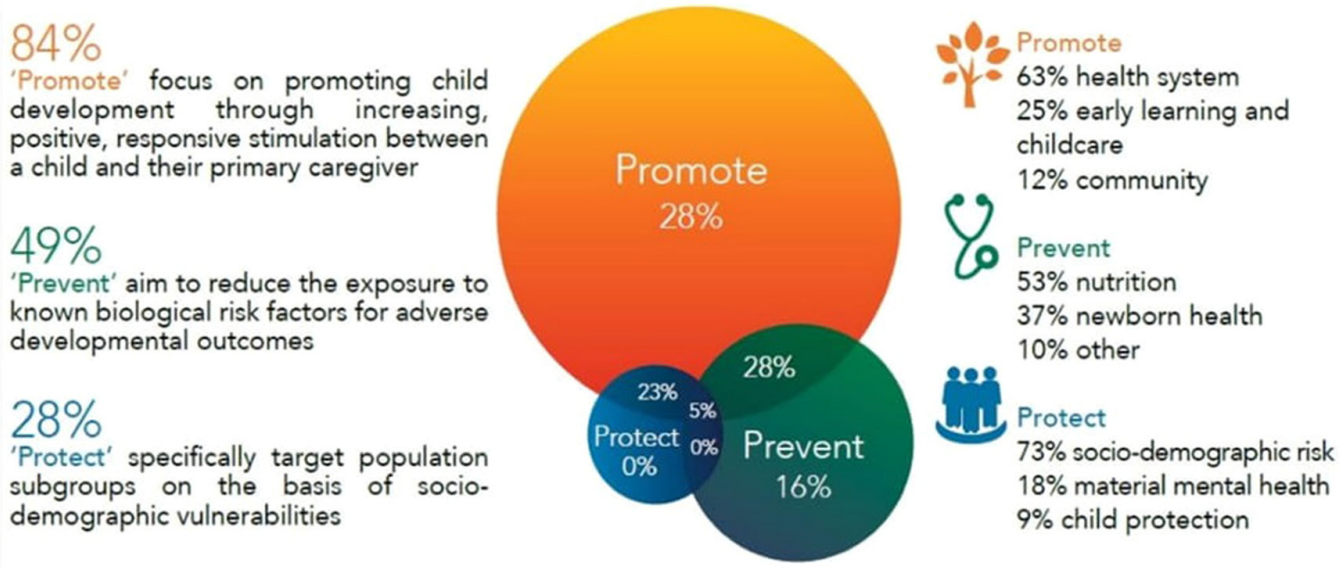

Figure 3 (A) Saving Brains projects included in evaluation ( $n=39,2011-2016)$. (B) Saving Brains projects according to sector and intervention focus. TTS, Transition to Scale. Source: Evaluation of Saving Brains portfolio.

evaluating programmes are also needed to deliver on calls for action in ECD.

\footnotetext{
Author affiliations

${ }^{1}$ Maternal, Adolescent, Reproductive and Child Health Centre, London School of Hygiene and Tropical Medicine, London, UK

${ }^{2}$ Murdoch Children's Research Institute, Melbourne, Victoria, Australia

${ }^{3}$ Economics Department, Universidad de los Andes, Bogota, Colombia

${ }^{4}$ Centro de Estudios de Desarrollo Economico (CEDE), Universidad de los Andes, Bogota, Colombia

${ }^{5}$ Maternal \& Child Health Intervention Research Group, Department of Population Health, London School of Hygiene and Tropical Medicine, London, UK

${ }^{6}$ Northern School of Paediatrics, Newcastle-upon-Tyne, UK

${ }^{7}$ Departamento de Pediatria, Faculdade de Medicina da Universidade de São Paulo, São Paulo, Brazil

${ }^{8}$ Early Child Development, UNICEF, New York City, New York, USA

${ }^{9}$ Department of Mental Health and Substance Abuse, World Health Organisation, Geneva, Switzerland

${ }^{10}$ Institute of Translational Medicine, University of Liverpool, Liverpool, UK

${ }^{11}$ Bernard van Leer Foundation, The Hague, The Netherlands

${ }^{12}$ Maternal and Child Health Division, International Centre for Diarrhoeal Disease Research Bangladesh, Dhaka, Dhaka District, Bangladesh

${ }^{13}$ Children's Investment Fund Foundation, London, UK

${ }^{14} \mathrm{~S}$ chool of Social and Community Medicine, University of Bristol, Bristol, UK

${ }^{15}$ Department of Paediatrics and Child Health, Muhimbili University of Health and Allied Sciences, Dar es Salaam, Tanzania

${ }^{16}$ Munk School of Global Affairs and Public Policy, University of Toronto, Toronto, Ontario, Canada
}

${ }^{17}$ Center on the Developing Child, Harvard University, Cambridge, Massachusetts, USA

${ }^{18}$ Department of Paediatrics and Child Health, Aga Khan University, Karachi, Pakistan

${ }^{19}$ Mobile Crèches, Sector IV, New Delhi, India

${ }^{20}$ Grand Challenges Canada, Toronto, Ontario, Canada

${ }^{21}$ Neonatal Medicine, University College London Hospitals NHS Trust, London, UK

Acknowledgements We thank all the innovators, participants and researchers involved in projects included in the Saving Brains portfolio and evaluation. We thank Grand Challenges Canada as funder of unpublished data. We thank the Early Child Development Expert Advisory Group for their guidance; and we are grateful to Claudia da Silva and Fion Hay for administrative assistance.

Contributors Technical oversight of the series was led by JEL and KMM. The first draft of the paper was undertaken by $\mathrm{KM}$. Other specific contributions were made by RBS, AB, PRB, TD, MG, EG, JH, RH, BK, MKL, HK, KM, VPH, JR, MAR, KLS, CT, JEL. The Early Child Development Expert Advisory Group (PRB, TD, EG, Sally Grantham-McGregor, MG, JH, RH, KM, JR, MAR, KLS, Arjun Upadhyay) contributed to the conceptual process throughout. All authors reviewed and agreed on the final manuscript.

Funding This supplement has been made possible by funding support from the Bernard van Leer Foundation. Saving Brains impact and process evaluation was funded by Grand Challenges Canada.

Disclaimer The authors alone are responsible for the views expressed in this article and they do not necessarily represent the views, decisions or policies of the institution with which they are affiliated.

Competing interests None declared. 
Provenance and peer review Commissioned; externally peer reviewed.

Data sharing statement All data within this research article are covered by a data sharing agreement as part of the Saving Brains, Grand Challenges Canada, grant with Saving Brains and other individual project teams. We are happy to provide further details on request.

Open access This is an open access article distributed in accordance with the Creative Commons Attribution Non Commercial (CC BY-NC 4.0) license, which permits others to distribute, remix, adapt, build upon this work non-commercially, and license their derivative works on different terms, provided the original work is properly cited, appropriate credit is given, any changes made indicated, and the use is non-commercial. See: http://creativecommons.org/licenses/by-nc/4.0/.

\section{REFERENCES}

1 United Nations. Sustainable Development Goals. 2015.

2 Every Woman Every Child. The Global Strategy for Women's, Children's and Adolescents' Health (2016-2030). 2015.

3 World Health Organisation. Nurturing Care Framework. Geneva: World Health Organisation, 2018. https://www.who.int/maternal_child_adolescent/documents/ nurturing-care-early-childhood-development/en/

4 Black MM, Walker SP, Fernald LCH, et al. Early childhood development coming of age: science through the life course. Lancet 2016;389:77-90.

5 Britto PR, Lye SJ, Proulx K, et al. Nurturing care: promoting early childhood development. Lancet 2016;389:91-102.

6 Britto PR, Singh M, Dua T, et al. What implementation evidence matters: scaling-up nurturing interventions that promote early childhood development. Ann N Y Acad Sci 2018;1419:5-16.

7 Lombardi J. What policymakers need from implementation evaluations of early childhood development programs. Ann N Y Acad Sci 2018;1419:17-19.

8 Stansbery P. Translation of evidence to practice to promote early childhood development programs. Ann N Y Acad Sci 2018;1419:23-5.

9 Saving Brains. Saving Brains, Grand Challenges Canada, 2018

10 Radner JM, Ferrer MJS, McMahon D, et al. Practical considerations for transitioning early childhood interventions to scale: lessons from the Saving Brains portfolio. Ann N Y Acad Sci 2018;1419:230-48.

11 Milner KM, Bhopal S, Dua T, et al. Counting outcomes, coverage and quality for early child development programmes. Arch Dis Child 2019;104(Suppl 1):S13-S21.

12 Boggs D, Milner KM, Black M, et al. Rating early child development outcome measurement tools for routine health programme use. Arch Dis Child 2019;104(Suppl 1):S22-S33.

13 Arregoces L, Hughes R, Tann C, et al. Accountability for funds for Nurturing Care: what can we measure? Arch Dis Child 2019;104(Suppl 1):S34-S42.

14 Cavallera V, Tomlinson M, Radner J, et al. Scaling early child development: what are the barriers and enablers? Arch Dis Child 2019;104(Suppl 1):S43-\$50.

15 World Health Organisation. The Global Accelerated Action for the Health of Adolescents (AA-HA!) Implementation Guidance, 2017.

16 World Health Organisation. Accelerating nutrition improvements in Sub-Saharan Africa: Scaling-up nutrition interventions final report 2012-2016. Geneva 2017.

17 Dickson KE, Kinney MV, Moxon SG, et al. Scaling up quality care for mothers and newborns around the time of birth: an overview of methods and analyses of intervention-specific bottlenecks and solutions. BMC Pregnancy Childbirth 2015;15(Suppl 2):S1

18 Hamadani JD, Mehrin SF, Tofail F, et al. Integrating an early childhood development programme into Bangladeshi primary health-care services: an open-label, clusterrandomised controlled trial. Lancet Glob Health 2019;7:e366-75.

19 Saving Brains. Request for proposals. http://www.grandchallenges.ca/saving-brains/

20 World Bank. World bank country and lending groups. 2018. https://datahelpdesk. worldbank.org/knowledgebase/articles/906519-world-bank-country-and-lendinggroups
21 Attanasio O, Baker-Henningham H, Bernal R, et al. Early Stimulation and Nutrition: the impacts of a scalable intervention. NBER Working Paper 2018. 25059.

22 Nores M, Fernandez C. Building capacity in health and education systems to deliver interventions that strengthen early child development. Ann N Y Acad SC 2018;1419:57-73.

23 Early Childhood Development Action Network. Homepage, 2018. Available: http:// www.ecdan.org/

24 Lawn JE, Blencowe $\mathrm{H}, \mathrm{Oza} \mathrm{S}$, et al. Every Newborn: progress, priorities, and potential beyond survival. Lancet 2014;384:189-205.

25 UNICEF. ECD Resource Pack, Module 4 Situational analysis for early child development. https://www.unicef.org/earlychildhood/index_42890.htm

26 Countdown to 2030. Country profiles for early childhood development. 2018. https:// nurturing-care.org/?page_id=703.

27 Yousafzai AK, Aboud F. Review of implementation processes for integrated nutrition and psychosocial stimulation interventions. Ann N Y Acad Sci 2014:1308:33-45.

28 Lo S, Das P, Horton R. A good start in life will ensure a sustainable future for all. Lancet 2017;389.

29 Murphy KM, Yoshikawa H, Wuermli AJ. Implementation research for early childhood development programming in humanitarian contexts. Ann N Y Acad SC 2018;1419:90-101.

30 Grand Challenges Canada. Creating hope in conflict: A humanitarian grand challenge. 2018 https://www.grandchallenges.ca/programs/creating-hope-conflict/.

31 Bonnier C. Evaluation of early stimulation programs for enhancing brain development. Acta Paediatr 2008:97:853-8.

32 Tessier R, Cristo M, Velez S, et al. Kangaroo mother care and the bonding hypothesis. Pediatrics 1998:102:e17.

33 Charpak N, Tessier R, Ruiz JG, et al. Twenty-year follow-up of kangaroo mother care versus traditional care. Pediatrics 2017:139:e20162063.

34 Charpak N, Ruiz-Pelaez JG, Figueroa de C Z, et al. A randomized, controlled trial of kangaroo mother care: results of follow-up at 1 year of corrected age. Pediatrics 2001;108:1072-9.

35 Smith JA, Baker-Henningham H, Brentani A, et al. Implementation of Reach Up early childhood parenting program: acceptability, appropriateness, and feasibility in Brazil and Zimbabwe. Ann N Y Acad Sci 2018;1419:120-40

36 Bajaj M, Sharma S. Scaling-up early childhood centres for migrant construction workers' children in India. Early Childhood Matters 2016;125:74-9.

37 Hamadani JD, Nahar B, Huda SN, et al. Integrating early child development programs into health and nutrition services in Bangladesh: benefits and challenges. Ann N Y Acad Sci 2014:1308:192-203.

38 Aboud FE, Moore AC, Akhter S. Effectiveness of a community-based responsive feeding programme in rural Bangladesh: a cluster randomized field trial. Matern Child Nutr 2008:4:275-86.

39 Aboud FE, Shafique S, Akhter S. A responsive feeding intervention increases children's self-feeding and maternal responsiveness but not weight gain. J Nutr 2009;139:1738-43.

40 Aboud FE, Akhter S. A cluster-randomized evaluation of a responsive stimulation and feeding intervention in bangladesh. Pediatrics 2011;127:e1191-e1197.

41 Hamadani JD, Huda SN, Khatun F, et al. Psychosocial Stimulation Improves the Development of Undernourished Children in Rural Bangladesh. J Nutr 2006;136:2645-52.

42 Tofail F, Hamadani JD, Mehrin F, et al. Psychosocial stimulation benefits development in nonanemic children but not in anemic, iron-deficient children. J Nutr 2013;143:885-93.

43 Nahar B, Hamadani JD, Ahmed T, et al. Effects of psychosocial stimulation on growth and development of severely malnourished children in a nutrition unit in Bangladesh. Eur J Clin Nutr 2009:63:725-31.

44 Nahar B, Hossain MI, Hamadani JD, et al. Effects of a community-based approach of food and psychosocial stimulation on growth and development of severely malnourished children in Bangladesh: a randomised trial. Eur J Clin Nutr 2012;66:701-9.

45 Secretaria do Desenvolvimento Urbano. Infocidade Prefeitura de Sao Paulo, 2012

46 Secretaria Municipal de Educacao. Prefeitura de Sao Paulo, 2012. 